\title{
Fine spatial pattern of an epiphytic lichen species is affected by habitat conditions in two forest types in the Iberian Mediterranean region
}

\author{
Rocío BELINCHÓN ${ }^{a, *}$, Isabel MARTÍNEZ ${ }^{a}$, Gregorio ARAGÓN ${ }^{a}$, Adrián ESCUDERO ${ }^{a}$, \\ Marcelino DE LA CRUZ \\ aÁrea de Biodiversidad y Conservación, Departamento de Biología y Geología, Universidad Rey Juan Carlos, E-28933 Móstoles, Spain \\ bepartamento de Biología Vegetal, E.U.I.T. Agrícola, Universidad Politécnica de Madrid, E-28040 Madrid, Spain
}

Keywords:

Dispersal

Forest management

Habitat quality

Lichens

Lobaria pulmonaria

Population ecology

\section{A B S T R A C T}

Persistence and abundance of species is determined by habitat availability and the ability to disperse and colonize habitats at contrasting spatial scales. Favourable habitat fragments are also heterogeneous in quality, providing differing opportunities for establishment and affecting the population dynamics of a species. Based on these principles, we suggest that the presence and abundance of epiphytes may reflect their dispersal ability, which is primarily determined by the spatial structure of host trees, but also by host quality. To our knowledge there has been no explicit test of the importance of host tree spatial pattern for epiphytes in Mediterranean forests. We hypothesized that performance and host occupancy in a favourable habitat depend on the spatial pattern of host trees, because this pattern affects the dispersal ability of each epiphyte and it also determines the availability of suitable sites for establishment. We tested this hypothesis using new point pattern analysis tools and generalized linear mixed models to investigate the spatial distribution and performance of the epiphytic lichen Lobaria pulmonaria, which inhabits two types of host trees (beeches and Iberian oaks). We tested the effects on L. puimonaria distribution of tree size, spatial configuration, and host tree identity. We built a model including tree size, stand structure, and several neighbourhood predictors to understand the effect of host tree on L. pulmonaria. We also investigated the relative importance of spatial patterning on the presence and abundance of the species, independently of the host tree configuration. L. pulmonaria distribution was highly dependent on habitat quality for successful establishment, i.e., tree species identity, tree diameter, and several forest stand structure surrogates. For beech trees, tree diameter was the main factor influencing presence and cover of the lichen, although larger lichen-colonized trees were located close to focal trees, i.e., young trees. However, oak diameter was not an important factor, suggesting that bark roughness at all diameters favoured lichen establishment. Our results indicate that $L$. pulmonaria dispersal is not spatially restricted, but it is dependent on habitat quality. Furthermore, new spatial analysis tools suggested that L. pulmonaria cover exhibits a distinct pattern, although the spatial pattern of tree position and size was random. 


\section{Introduction}

Given the alarming rate of habitat destruction at a global scale, there is an urgent need to understand how species persist in highly dynamic habitats from both spatial and temporal perspectives (Stewart et al. 2000; Hanski 2005; Pharo \& Zartman 2007). Theoretical and empirical animals and plant studies have tried to elucidate how organisms use spatially distributed resources, and the consequences of resource distribution for population-level processes (Tilman \& Kareiva 1997; Lancaster \& Downes 2004). Some studies suggest that resource distribution patterns at spatial and temporal scales can influence the dynamics of populations and communities. This was also suggested by the recovery of species in disturbed ecosystems in a metapopulation model (Levin et al. 2003; Hanski 2005). Thus, the persistence and abundance of species is determined by a dynamic balance between habitat availability and the ability of a species to disperse and colonize habitats at different spatial scales (Hanski 2005; Jönsson et al. 2008).

Population dynamics and specific establishment patterns are strongly affected by the spatial patterns of certain abiotic and biotic factors and mobility, including the structure of adequate habitats and the dispersal potential of a species (Nathan \& Muller-Landau 2000). In the case of epiphytes, there is an ongoing debate on whether species distribution is limited by dispersal or habitat limitation in fragmented, highly heterogeneous environments (Werth et al. 2006). Thus, species distribution patterns could show spatial structuring due to spatially structuring of the habitat, limited dispersal ability, or a combination of both these factors (Hedenås et al. 2003). Habitat spatial patterning is also related to the patchy distribution of host trees and their spatial density, which may vary considerably between patches and over time (Snäll et al. 2004, 2005). Epiphytes need to track and respond to these dynamic patches to persist at different hierarchical spatial scales (Snäll et al. 2003, 2005). Epiphytes can respond to the spatial configuration of forest remnants (Snäll et al. 2004; Öckinger et al 2005), including the matrix structure (Belinchón et al. 2009), and they can respond to tree stand configuration and structure at a lower nesting of the spatial scale (Gu et al. 2001; Hedenås et al. 2003).

Factors, such as tree size, tree age, microclimatic conditions, and forest quality, have been studied to better understand colonization by epiphytic organisms (Hedenås et al. 2003; Snäll et al. 2003, 2004; Edman et al. 2008). However, distance-dependent dispersal cannot be ignored (Walser 2004; Öckinger et al. 2005; Pharo \& Zartman 2007; Johansson 2008). A growing body of literature is devoted to assess the influence of the nearest tree distance on the dynamics of epiphytic populations (e.g., Gu et al. 2001; Kalwij et al. 2005; Snäll et al. 2005; Bolli et al. 2008). It remains unknown how dispersal actually limits and regulates the distribution of epiphytes, and how it interacts with habitat structure and quality (Heegaard \& Hangelbroek 1999; Scheidegger \& Werth 2009). Gu et al. (2001) indicated that the distance between a noncolonized tree and the nearest colonized neighbouring tree provides a measure of the likelihood of colonization.

The basic demographic processes of epiphytic lichens can be classified into three distinct stages: (1) dispersal of propagules; (2) establishment of thalli; and (3) growth of established thalli (Bailey 1976; Sillett et al. 2000), with germination probably being the most critical stage (Hilmo \& Såstad 2001). Based on this knowledge, previous studies have evaluated the underlying process of epiphytic distribution, focussing on dispersal and establishment. Species dispersal can be limited by distance (Dettki et al. 2000; Zoller et al. 2000; Walser 2004), depending on the reproduction mode (Hedenås et al. 2003; Löbel et al. 2009), while establishment can be dependent on habitat quality (Werth et al. 2006; Heinken et al. 2007; Lättman et al. 2009).

Lichens can reproduce using sexual or asexual structures (Scheidegger \& Werth 2009). Lobaria pulmonaria reproduces asexually via relatively large vegetative soredia or isidioid soredia (both symbionts are dispersed together), and sexually by means of ascospores that disperse only the mycobionts, which are formed in a late stage of thallus development (Scheidegger 1995; Denison 2003). There is a negative correlation between diaspore size and dispersal (Tackenberg et al. 2003). Most sexual spores are distinctly smaller than asexual diaspores, suggesting that sexual reproduction is better adapted to long distance dispersal (Hedenås et al. 2003; Johansson 2008).

Molecular and empirical studies show that L. pulmonaria can efficiently disperse their vegetative propagules up to $200 \mathrm{~m}$ (Walser 2004; Öckinger et al. 2005; Werth et al. 2006). Although long distance-dispersal cannot, however, be discarded (Scheidegger \& Werth 2009). However, the majority of L. pulmonaria vegetative propagules were detected at a very short spatial scale, i.e., $<40 \mathrm{~m}$ (Werth et al. 2006). Thus, if propagule dispersal rain is dense and efficient at short distances, it is not clear why many trees remain noncolonized in a forest remnant and what factors determine the likelihood of colonization.

We investigated the relative importance of forest remnant habitat quality and structure on L. pulmonaria performance and colonization likelihood, by examining its spatial pattern (i.e., presence/absence and abundance) at a fine tree-to-tree scale on two different host tree species, Fagus syluatica and Quercus pyrenaica.

Several recent studies have investigated the fundamental niche of L. pulmonaria (Walser 2004; Öckinger et al. 2005; Werth et al. 2006; Belinchón et al. 2009). We previously showed (Belinchón et al. 2009) that both the level of forest fragmentation and the quality and nature of the surrounding landscape matrix affect L. pulmonaria populations. Our results indicated that in fragmented landscapes, patch quality (tree species and stand structure) and the nature of the landscape matrix (pine plantations and shrub formations) exert more influence than other landscape features, such as patch size and isolation.

However, the importance of dispersal at small spatial scales and how the spatial configuration of host trees influences performance and the probability that a tree might be colonized by L. pulmonaria remains to be evaluated. The latter question is challenging, because the effect of host spatial patterning has never been evaluated in an epiphyte.

Colonization should not be affected by dispersal limitation at small spatial scales, so we hypothesized that other local factors may determine the probability of colonization and performance, such as tree size and the spatial configuration of trees, which depends on the host tree identity. These factors 
will impart a characteristic spatial signature on epiphyte occurrence. We assumed that old trees act as dispersal sources and tested our hypothesis following a two-fold approach. First, we built a mixed model using a classical modelling approach, to evaluate the influence on the occurrence and cover of L. pulmonaria on individual young host trees of different key factors such as tree diameter, number of trees per plot, and a neighbourhood index. Second, we analysed spatial patterns in the presence/absence and abundance of L. pulmonaria, and tested those patterns against the predictions of the models produced in the first step. The second approach was critical, because evaluation of the spatial configuration of L. pulmonaria in the remnants depended on the spatial patterning of trees. Previous studies report a strong spatial dependence between epiphytes and host spatial structure, but this is an obvious result because epiphytic lichens can only occur on trees and must be absent when trees are absent. Thus, we conducted a spatial point pattern analysis approach where we partitioned out the spatial structure of trees and incorporated the effects of certain local factors, to identify the characteristic spatial structure of L. pulmonaria independent of the host configuration.

\section{Material and methods}

\section{Study site and study species}

The study area was c. 5600 ha in the Sierra de Ayllón, which is located on the easternmost tip of the Sistema Central Range in Spain ( $\left.41^{\circ} 13^{\prime} N 3^{\circ} 21^{\prime} \mathrm{W}\right)$. The topography is undulating and the elevation ranges from 1441 to 1835 m.a.s.l. The climate is Mediterranean with a mean annual temperature of $8.6^{\circ} \mathrm{C}$ and an annual rainfall of $1253 \mathrm{~mm}$ (climatic station Cerezo de Arriba, 'La Pinilla', 1500 m.a.s.l.), with an extreme drought period from Jul. to Aug. that is attenuated by summer storms.

The landscape consists of a mosaic of 23 forest remnants of beech (Fagus sylvatica) and eight Mediterranean oak remnants (Quercus pyrenaica), which are embedded in a matrix dominated by heathland (Erica arborea and Erica australis) and pine afforestations (Pinus sylvestris). Quercus pyrenaica is a semideciduous oak with a range that is almost entirely restricted to the Iberian Peninsula, but with some isolated populations in northern Morocco and the southwest tip of France. Fagus sylvatica is a deciduous tree widespread throughout Western Europe and its southwestern distribution limit is found in these mountains (Costa Tenorio et al. 1998).

The study area has experienced forest loss and fragmentation over many centuries. Between the 16th and 19th centuries, many beech and oak forests were turned into pasture and heathland, so only forest fragments and isolated trees remain. Logging and charcoal production were the main use of the forest remnants. Thus, conversion to coppice stands was the norm. In the 1960s, most coppice stands and heathlands were turned into pine afforestations (Hernández \& Sainz 1978). The current landscape is highly fragmented, with well-preserved forests restricted to areas with difficult access.

Lobaria pulmonaria is an epiphytic green-algal macrolichen with internal cephalodia with Nostoc. It is one of the most commonly used indicators of unpolluted and undisturbed forests (Kuusinen 1996), because of its limited dispersal ability (Werth et al. 2006) and its susceptibility to excessive light (Gauslaa \& Solhaug 2001). It is widespread throughout the northern hemisphere, but populations have declined considerably over the last century due to forest destruction, intensive forest management, and air pollution (Purvis et al. 1992). It mainly occurs in the northern fringes of the Iberian Peninsula, but it reaches some mountainous localities in the centre and south. However, the species is currently declining in the Mediterranean region, where forests with mesic requirements are extremely rare due to a variety of reasons, including wood extraction, grazing by cattle, meadow management, and global warming (Martínez et al. 2003).

\section{Sampling}

Field work was conducted between 2006 and 2008. The present study was based on 17 plots used in a previous study based on the Sierra de Ayllón (see Belinchón et al. 2009). The plot size was $20 \times 20 \mathrm{~m}$ and plots were randomly located in different forest remnants in the study landscape. In total, 12 and five plots were evaluated for beech and oak remnants, respectively. For monitoring purposes, we established a minimum diameter at breast height (dbh) for each host tree species. This was the minimum size determined for Lobaria pulmonaria in previous field studies investigating the demography of $L$. pulmonaria throughout the Iberian Peninsula. In each plot, we used GPS coordinates to map each host tree in the stand plot by direct measurement and triangulation from the corners of the sample plot. For beech trees the minimum $\mathrm{dbh}$ was $9 \mathrm{~cm}$, while for oak trees the minimum dbh was $7 \mathrm{~cm}$. The total number of trees was used to calculate the mean $\mathrm{dbh}$ in each plot. A total of 656 trees were surveyed. The presence of $\mathrm{L}$. pulmonaria below $2 \mathrm{~m}$ height was recorded. This height was chosen because $L$. pulmonaria rarely occurs above this height in the region (Belinchón et al. 2009). Cover of L. pulmonaria was measured in square centimetres, by tracing L. pulmonaria thalli on transparent plastic sheets. Species cover was then calculated using an image analyzer (ImageJ $1.36 \mathrm{~b}$ National Institutes of Health, USA).

\section{Statistical analysis}

We assumed that dispersal and colonization mainly pass from older trees to younger ones (Belinchón et al. 2009). We analysed the size ( $\mathrm{dbh}$ ) structure of all measured trees and trees were classified as 'young' when the dbh was within the lower quartile of the total distribution (i.e., for young beeches $\mathrm{dbh}$ $<30 \mathrm{~cm}$ and for young oaks $\mathrm{dbh}<17.5 \mathrm{~cm}$ ), while all other trees were classified as 'older'. The influence of the local environment on the probability of colonization was tested by selecting all the young trees in an $8 \mathrm{~m} \times 8 \mathrm{~m}$ subplot at the centre of each $20 \mathrm{~m} \times 20 \mathrm{~m}$ plot. This guaranteed that edge effects would not bias the analysis.

We estimated the influence of Lobaria pulmonaria abundance in neighbouring trees on the presence and abundance of L. pulmonaria on young trees by computing an influence index, modified from Firbank \& Watkinson (1987). This index summed the abundance of L. pulmonaria in neighbouring trees and weighted them by the inverse of the distance to the target 
tree. The index is computed as follows:

$I_{N}=\sum_{i}^{n} \frac{C_{i}}{\operatorname{dist}(i, f)}$

where $C_{i}$ is the amount of $L$. pulmonaria cover found on each of the $n$ neighbours that was greater than the focal tree in a $6 \mathrm{~m}$ radius of the focal tree, while dist $(i, f)$ is the distance between the neighbour and the focal tree.

We measured the distance between a young focal tree (colonized or noncolonized) and it's surrounding occupied older neighbours. The dynamics of L. pulmonaria differ depending on the forest type (Belinchón et al. 2009), so separate influence indices $\left(I_{N}\right)$ were calculated for beech and oak trees.

We evaluated the influence of local variables on the performance of L. pulmonaria in young trees by fitting generalized linear mixed models (GLMMs) to the abundance and presence data. The models included three predictors to describe the local environment at three different scales: dbh of the focal tree (small scale), influence index (medium scale), and total number of trees per plot (large scale). We also tested plot (i.e., an indicator predictor) as a random factor to identify any hidden correlations between data from the same plot. GLMMs were fitted using procedures GLIMMIX and GENMOD in SAS ver. 9.0 (SAS Institute, Cary, NC). We ran a complete model with host types, but finally focussed on different models for beech and oak as hosts, because the interpretation of local factors in the complete models was confounded by the strong main effect of host type. We used a binomial distribution with a logit link function to model the presence data and a Poisson distribution with a log link function to model L. pulmonaria cover. Poisson distribution is usually employed to fit count data, but inspection of our cover data also confirmed that this distribution fitted our data better than alternative distributions, such as the normal distribution.

Epiphytes are influenced by their substrate, so analysis of the spatial pattern of epiphytic lichens may be controlled by the underlying distribution of their host trees (Gu et al. 2001; Hedenås et al. 2003). We analysed the spatial pattern of beech and oak trees using Ripley's K-function (Ripley 1988). This method is distance-based and is used to estimate the expected number of neighbours within a distance $r$ of each target tree. To simplify the display of the result, $K(r)$ was transformed in to the frequently used linearized version $L(r)$ :

$L(r)=[K(r) / \pi]^{1 / 2}-r$

where $K(r)$ is the estimated Ripley's $K$ function. The L function estimate at a given distance $r, L(r)$, is expected to be zero when points are randomly distributed. Positive values of $L(r)$ indicate spatial aggregation, whereas negative values indicate uniformity (Diggle 1983; Dale 1999). A Monte Carlo simulation was used to evaluate the significance of $L(r)$ deviations from zero (Upton \& Fingleton 1985). We computed $99 \%$ envelopes for the $L(r)$ generated by 99 Complete Spatial randomness (CSR) simulations. The spatial pattern of beech and oak tree diameters was also analysed using the normalized mark-weighted $K$ function $\left(K_{\mathrm{mm}}\right)$. This functional data summary measures the joint pattern of points and marks at different scales (Penttinen 2006; De la Cruz 2008). Inference was based on a computation of simulation envelopes using 99 random relabellings of tree diameters from the original set of coordinates. The normalized $K_{\mathrm{mm}}$ results from the ratio between the mark-weighted $\mathrm{K}$-function and the raw plain $\mathrm{K}$-function, so no edge correction was necessary.

The spatial pattern of the L. pulmonaria distribution in each plot was analysed by testing a hypothesis that the spatial pattern of colonized and noncolonized trees was mediated by the fitted logistic and Poisson models for presence and cover, respectively. We computed the difference, $K_{1}-K_{2}$, between the Ripley's $K$ functions of the colonized and noncolonized trees (Dixon 2002; De la Cruz 2008). We then evaluated a model comparing the observed difference $K_{1}-K_{2}$ with the confidence envelopes of the $K$ function differences generated by 99 simulations of the fitted mixed models. Each simulation consisted of labelling the trees as L. pulmonaria present or absent, based on a predicted occurrence probability. The probability of labelling each tree was randomly obtained using a normal probability distribution with a mean equal to the fitted value of the binomial mixed model for L. pulmonaria occurrence on an actual tree and its corresponding standard error (Olano et al. 2009). In this case, the isotropic method of Ripley (Ripley 1988) was used to correct edge effects. We also evaluated the spatial structure of L. pulmonaria cover in each plot using the normalized mark-weighted $K$ function (' $\mathrm{K}_{\mathrm{mm}}$ '). We compared the observed $K_{\mathrm{mm}}$ with the confidence envelopes generated from 99 simulations of the fitted model. Each simulation assigned a cover value to each tree, which was predicted from the fitted Poisson model.

Spatial analyses were performed in the $\mathrm{R}$ environment (R Development Core Team 2007; http://www.R-Project.org), using the spatstat (Baddeley \& Turner 2005) and ecespa (De la Cruz 2008) packages.

\section{Results}

Analysis of stand structural characteristics showed that the mean diameter of trees in oak plots was smaller than that of beech plots (Mann-Whitney test: $z=-2.63 ; p=0.008$; $n_{1}=12 ; n_{2}=5$; Table 1 ). The number of trees per plot varied depending on the plot, reflecting the high forest heterogeneity in our data set (Table 1). Oak plots had significantly more trees per plot than beech plots (Mann-Whitney test: $z=-2.11$; $p=0.035 ; n_{1}=12 ; n_{2}=5$; Table 1 ). The number of trees occupied by Lobaria pulmonaria was also highly variable among plots, although the highest number was found in oak plots (Man$n-W h i t n e y$ test: $z=-1.01 ; p=0.311 ; n_{1}=12 ; n_{2}=5$; Table 1 ). The percentage of trees occupied by $L$. pulmonaria was also higher in oak plots (Mann-Whitney test: $z=-1.26 ; p=0.206$; $n_{1}=12 ; n_{2}=5$; Table 1). The coefficient of variation for tree diameter in each plot indicated that oak plots were more homogeneous than beech ones, and the differences between the two types may be related to forest management (Mann-Whitney test: $z=-2.32 ; p=0.020 ; n_{1}=12 ; n_{2}=5$; Table 1 ).

The models showed there were different responses in terms of L. pulmonaria presence and cover between the two tree species (Table $2 \mathrm{a}$ and $\mathrm{b}$ ). We used the GLIMMIX procedure for beech fragments to estimate the predictors at different hierarchical levels, because the random variable plot was highly significant for beech (Belinchón et al. 2009). This was not the case for oak forest stands, so we applied the GENMOD procedure (plot variable was not significant in hierarchical models; see Belinchón et al. 2009). In beech plots, the diameter of the host tree was 
Table 1 - Description of stand structural characteristics for the 17 plots sampled. Host tree: FS, beech trees (Fagus syluatica); $Q P$, oak trees (Quercus pyrenaica). DBH: Mean tree diameter \pm standard deviation and range between parentheses. CV: coefficient of variation was calculated from the means and standard deviations of DBH.

\begin{tabular}{|c|c|c|c|c|c|c|}
\hline Plot & $\begin{array}{l}\text { Host } \\
\text { tree }\end{array}$ & $\begin{array}{l}N^{\circ} \text { trees } \\
\text { per plot }\end{array}$ & $\begin{array}{c}N^{\circ} \text { occupied } \\
\text { trees }\end{array}$ & $\begin{array}{c}\% \text { occupied } \\
\text { trees }\end{array}$ & $\mathrm{DBH}$ & GV \\
\hline 1 & FS & 22 & 9 & $40.90 \%$ & $30.30 \pm 8.80(14.01-44.59)$ & 0.290 \\
\hline 2 & FS & 22 & 5 & $22.72 \%$ & $32.32 \pm 16.31(12.10-86.62)$ & 0.505 \\
\hline 3 & FS & 35 & 11 & $31.42 \%$ & $20.26 \pm 6.25(12.10-41.40)$ & 0.309 \\
\hline 4 & FS & 26 & 8 & $30.77 \%$ & $32.31 \pm 17.29(14.01-79.94)$ & 0.535 \\
\hline 5 & FS & 21 & 10 & $47.62 \%$ & $31.01 \pm 10.95(13.38-58.92)$ & 0.353 \\
\hline 6 & FS & 18 & 9 & $50 \%$ & $31.72 \pm 13.51(10.19-60.51)$ & 0.426 \\
\hline 7 & FS & 26 & 10 & $38.46 \%$ & $29.43 \pm 18.39(12.10-92.68)$ & 0.638 \\
\hline 8 & FS & 45 & 10 & $22.22 \%$ & $24.99 \pm 14.86(10.83-83.44)$ & 0.595 \\
\hline 9 & FS & 25 & 17 & $68 \%$ & $33.44 \pm 21.98(15.92-121.02)$ & 0.657 \\
\hline 10 & FS & 21 & 10 & $47.62 \%$ & $39.51 \pm 14.27(14.33-66.24)$ & 0.369 \\
\hline 11 & FS & 72 & 22 & $30.55 \%$ & $16.37 \pm 6.77(9-54.46)$ & 0.414 \\
\hline 12 & FS & 16 & 9 & $56.25 \%$ & $47.23 \pm 14.21(24.20-69.75)$ & 0.301 \\
\hline 13 & $Q P$ & 24 & 19 & $79.16 \%$ & $28.20 \pm 13.05(10.51-52.87)$ & 0.463 \\
\hline 14 & $Q P$ & 60 & 24 & $40 \%$ & $18.05 \pm 5.29(8.92-30.57)$ & 0.293 \\
\hline 15 & $Q P$ & 122 & 33 & $27.05 \%$ & $11.22 \pm 2.89(7-24.52)$ & 0.258 \\
\hline 16 & $Q P$ & 63 & 6 & $9.52 \%$ & $15.84 \pm 4.03(8.60-23.57)$ & 0.254 \\
\hline 17 & $Q P$ & 38 & 9 & $23.68 \%$ & $17.38 \pm 3.06(11.15-25.48)$ & 0.176 \\
\hline
\end{tabular}

the most important predictor explaining L. pulmonaria presence and cover. However, presence and cover was not affected by the number of beech trees per plot, or the influence index (Table 2a). Results for the oak plots show that lichen presence was explained by the influence index $\left(I_{N}\right)$. Presence of $L$. pulmonaria increased if the target oak tree was surrounded by nearby occupied trees (Table $2 b$ ). Abundance was also negatively affected by the number of trees per plot.

Point pattern spatial analyses indicated that the spatial pattern of tree diameter was randomly distributed for both host tree species (data not shown). The spatial pattern of lichen presence matched the predictions of the logistic GLMM model, as suggested by the results of the difference $\mathrm{K}_{1}-\mathrm{K}_{2}$ analysis (Fig $1 \mathrm{~A}$ and Table $3 \mathrm{a}$ ). Similar results were obtained using a simulation with a null model of random labelling, although the confidence envelopes were closer (data not shown). However, we found a different spatial pattern for L. pulmonaria cover, as shown by our results using markweighted $K$ functions (Fig 1B and Table 3b). A clumped pattern was the most common for L. pulmonaria cover in oak plots $(60 \%)$. However, L. pulmonaria cover did not follow a specific trend in most beech plots.

\section{Discussion}

Our results suggest that the establishment and growth of Lobaria pulmonaria are highly dependent on habitat quality (tree host). However, the abundance of this lichen differed between host trees and was related to the forest structure. Therefore, not all trees were equally suitable for L. pulmonaria colonization and growth. The random patterning of lichen

Table 2 - (a) Results from GLMM examining L. pulmonaria traits on beech plots. The random variable 'plot' was significant in both cases: $L$. pulmonaria occurrence $(z$-value $=2.22 ;$ Prob $=0.013)$, L. pulmonaria cover $(z$-value $=2.23 ;$ Prob $=0.013)$. (b) Results from generalized linear model (GLM) examining how oak variables influence $L$. pulmonaria presence and cover. Goodness of fit is evaluated by means of the change in deviance and the corresponding $\chi^{2}$ test. $I_{N}=$ influence index; $\mathrm{Narb}=$ number of trees per plot. Sign $=$ sign of the coefficient of the variable in both models. Dbh = tree diameter. Boldface values represent significant factors.

\begin{tabular}{|c|c|c|c|c|c|c|}
\hline \multirow[t]{2}{*}{ (a) } & \multicolumn{3}{|c|}{ Occurrence of L. pulmonaria } & \multicolumn{3}{|c|}{ Cover of L. pulmonaria } \\
\hline & Sign & $F$-value & $p$-value & Sign & F-value & $p$-value \\
\hline$I_{\mathrm{N}}$ & + & 0.68 & 0.410 & + & 0.01 & 0.916 \\
\hline Narb & - & 0.00 & 0.952 & + & 0.48 & 0.496 \\
\hline Dbh & + & 10.19 & 0.002 & + & 5.39 & 0.022 \\
\hline \multirow[t]{2}{*}{ (b) } & \multicolumn{3}{|c|}{ Occurrence of L. pulmonaria } & \multicolumn{3}{|c|}{ Cover of L. pulmonaria } \\
\hline & Sign & $\chi^{2}$ test & $p$-value & Sign & $\chi^{2}$ test & $p$-value \\
\hline$I_{N}$ & + & 9.38 & 0.002 & + & 3.03 & 0.081 \\
\hline Narb & - & 1.44 & 0.229 & - & 11.85 & $<0.001$ \\
\hline Dbh & - & 0.04 & 0.837 & + & 0.37 & 0.542 \\
\hline
\end{tabular}



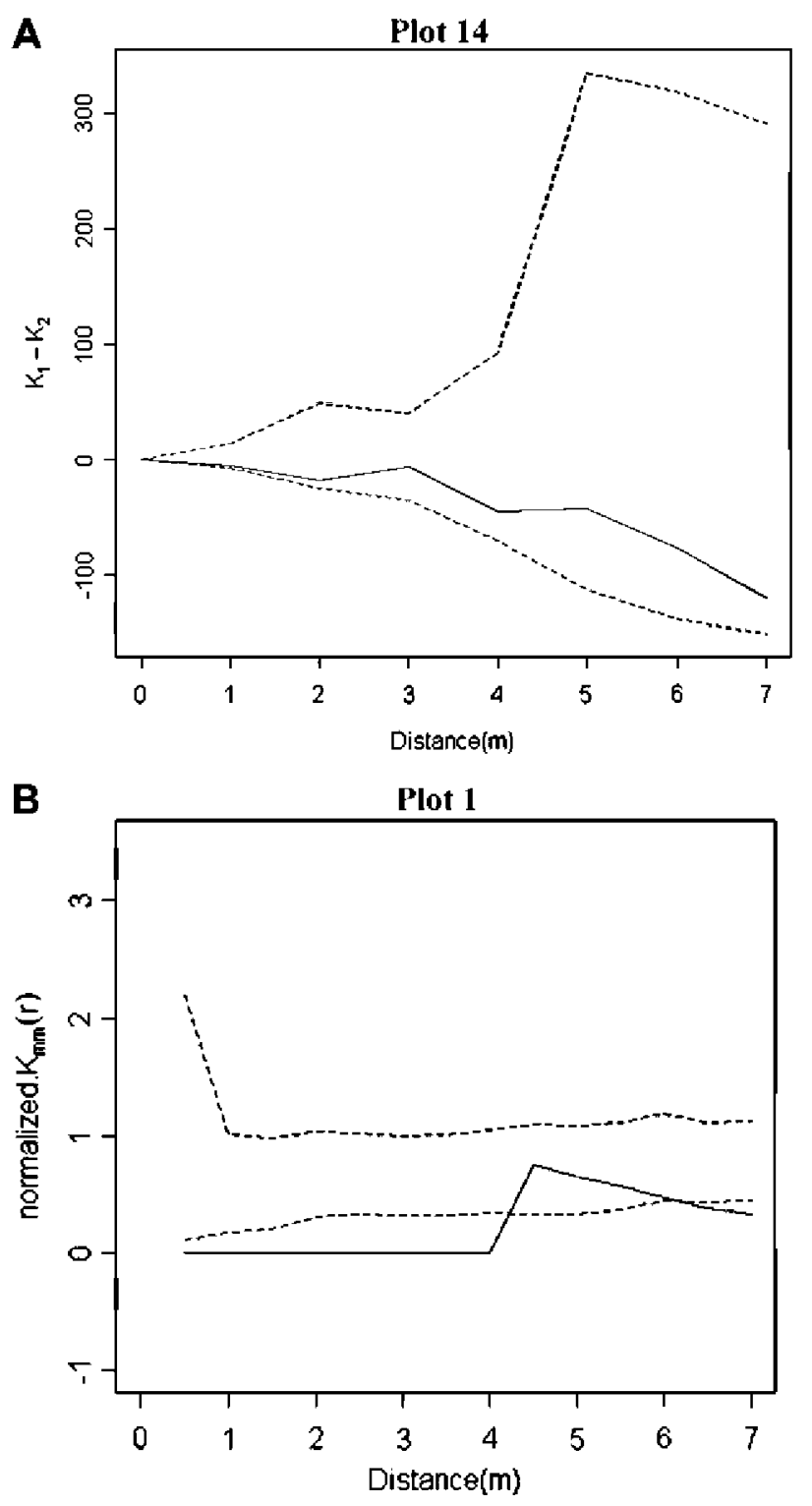

Fig 1 - (A) Diagram showing an example of the distribution of L. pulmonaria presence (random distribution). (B) Diagram showing an example of the spatial pattern of $L$. pulmonaria cover in a plot (regular distribution). Solid line is (A) observed $K_{1}-K_{2}(r)$ and $(B)$ observed $K_{m m}$; dashed lines: $95 \%$ confidence limits obtained from 99 simulations.

presence indicated that dispersal did not seem to be a limitation. Propagules could arrive on any available tree at random, but there performance was highly variable thereafter. We found that host tree, tree diameter, and stand structure were limiting factors in the establishment and growth of propagules.

Previous studies have shown that epiphytic lichen distribution is regulated by dispersal ability and establishment limitation, at both regional and local scales (Gu et al. 2001; Hedenås et al. 2003; Snäll et al. 2003; Öckinger et al. 2005; Löbel et al. 2006). However, the generality and applicability of dispersal limitation on epiphytic lichens remain controversial, because of contradictory results concerning the spatial aggregation of
Table 3 - Spatial pattern of L. pulmonaria in 17 plots of beech and oak stands. Data represent (a) presence of L. pulmonaria for each forest type; (b) cover of

L. pulmonaria in each forest type. Data for each stand are from a $20 \times 20 \mathrm{~m}$ mapped plot. Spatial pattern analyses were performed by (a) $K_{1}-K_{2}$ function with presence data and (b) $K_{m m}$ function with cover data. $G$ indicates clumped distribution; $\mathrm{U}$ indicates uniform distribution and $\mathbf{R}$ indicates random distribution. Significance was evaluated by using $99 \%$ Monte Carlo confidence intervals (99 simulations) with a $1 \mathrm{~m}$ step.

(a)

Distance $(\mathrm{m})$

\begin{tabular}{ccccccccc} 
& & $0-1$ & $1-2$ & $2-3$ & $3-4$ & $4-5$ & $5-6$ & $6-7$ \\
\hline Beech plots & 1 & $\mathrm{R}$ & $\mathrm{R}$ & $\mathrm{R}$ & $\mathrm{R}$ & $\mathrm{R}$ & $\mathrm{R}$ & $\mathrm{R}$ \\
& 2 & $\mathrm{R}$ & $\mathrm{R}$ & $\mathrm{R}$ & $\mathrm{R}$ & $\mathrm{R}$ & $\mathrm{R}$ & $\mathrm{R}$ \\
& 3 & $\mathrm{R}$ & $\mathrm{R}$ & $\mathrm{R}$ & $\mathrm{R}$ & $\mathrm{R}$ & $\mathrm{R}$ & $\mathrm{R}$ \\
& 4 & $\mathrm{R}$ & $\mathrm{R}$ & $\mathrm{R}$ & $\mathrm{R}$ & $\mathrm{R}$ & $\mathrm{R}$ & $\mathrm{C}$ \\
& 5 & $\mathrm{R}$ & $\mathrm{R}$ & $\mathrm{R}$ & $\mathrm{R}$ & $\mathrm{R}$ & $\mathrm{R}$ & $\mathrm{R}$ \\
& 6 & $\mathrm{R}$ & $\mathrm{R}$ & $\mathrm{R}$ & $\mathrm{R}$ & $\mathrm{R}$ & $\mathrm{R}$ & $\mathrm{R}$ \\
& 7 & $\mathrm{R}$ & $\mathrm{R}$ & $\mathrm{R}$ & $\mathrm{R}$ & $\mathrm{R}$ & $\mathrm{R}$ & $\mathrm{R}$ \\
& 8 & $\mathrm{R}$ & $\mathrm{R}$ & $\mathrm{R}$ & $\mathrm{R}$ & $\mathrm{R}$ & $\mathrm{R}$ & $\mathrm{R}$ \\
& $\mathrm{9}$ & $\mathrm{R}$ & $\mathrm{R}$ & $\mathrm{R}$ & $\mathrm{R}$ & $\mathrm{R}$ & $\mathrm{R}$ & $\mathrm{R}$ \\
& 10 & $\mathrm{R}$ & $\mathrm{R}$ & $\mathrm{R}$ & $\mathrm{R}$ & $\mathrm{R}$ & $\mathrm{R}$ & $\mathrm{U}$ \\
& 11 & $\mathrm{R}$ & $\mathrm{C}$ & $\mathrm{C}$ & $\mathrm{C}$ & $\mathrm{C}$ & $\mathrm{C}$ & $\mathrm{C}$ \\
& 12 & $\mathrm{R}$ & $\mathrm{R}$ & $\mathrm{R}$ & $\mathrm{R}$ & $\mathrm{R}$ & $\mathrm{R}$ & $\mathrm{R}$ \\
& 13 & $\mathrm{R}$ & $\mathrm{R}$ & $\mathrm{R}$ & $\mathrm{C}$ & $\mathrm{C}$ & $\mathrm{R}$ & $\mathrm{R}$ \\
& 14 & $\mathrm{R}$ & $\mathrm{R}$ & $\mathrm{R}$ & $\mathrm{R}$ & $\mathrm{R}$ & $\mathrm{R}$ & $\mathrm{R}$ \\
& 15 & $\mathrm{R}$ & $\mathrm{R}$ & $\mathrm{R}$ & $\mathrm{R}$ & $\mathrm{R}$ & $\mathrm{R}$ & $\mathrm{R}$ \\
& 16 & $\mathrm{R}$ & $\mathrm{R}$ & $\mathrm{R}$ & $\mathrm{R}$ & $\mathrm{R}$ & $\mathrm{R}$ & $\mathrm{R}$ \\
& 17 & $\mathrm{R}$ & $\mathrm{R}$ & $\mathrm{R}$ & $\mathrm{C}$ & $\mathrm{C}$ & $\mathrm{C}$ & $\mathrm{C}$ \\
\hline
\end{tabular}

(b) Distance $(\mathrm{m})$

\begin{tabular}{|c|c|c|c|c|c|c|c|c|}
\hline & & $0-1$ & $1-2$ & $2-3$ & $3-4$ & $4-5$ & $5-6$ & $6-7$ \\
\hline \multirow[t]{12}{*}{ Beech plots } & 1 & $\mathrm{U}$ & $\mathrm{U}$ & $\mathrm{U}$ & $\mathrm{R}$ & $\mathrm{R}$ & U & $\mathrm{U}$ \\
\hline & 2 & $\mathrm{U}$ & $\mathrm{U}$ & $\mathrm{U}$ & C & C & $\mathrm{U}$ & $\mathrm{U}$ \\
\hline & 3 & $\mathbf{U}$ & $\mathrm{U}$ & $\mathrm{U}$ & $\mathrm{U}$ & $\mathrm{C}$ & $\mathrm{C}$ & $\mathrm{U}$ \\
\hline & 4 & $\mathrm{R}$ & $\mathrm{C}$ & $\mathrm{C}$ & C & $\mathrm{C}$ & $\mathrm{C}$ & $\mathrm{R}$ \\
\hline & 5 & $\mathrm{U}$ & $\mathrm{U}$ & $\mathrm{U}$ & $\mathrm{C}$ & $\mathrm{C}$ & $\mathrm{U}$ & $\mathrm{U}$ \\
\hline & 6 & $\mathrm{R}$ & $\mathrm{R}$ & C & C & C & C & $\mathrm{C}$ \\
\hline & 7 & $\mathrm{U}$ & $\mathrm{U}$ & $\mathrm{C}$ & $\mathrm{R}$ & $\mathrm{U}$ & $\mathrm{U}$ & $\mathrm{U}$ \\
\hline & 8 & C & C & $\mathrm{U}$ & $\mathrm{U}$ & C & $C$ & $\mathrm{U}$ \\
\hline & 9 & $\mathrm{R}$ & $\mathrm{C}$ & $\mathrm{C}$ & $\mathrm{R}$ & $\mathrm{R}$ & C & $\mathrm{R}$ \\
\hline & 10 & $\mathrm{R}$ & $C$ & $C$ & $\mathrm{R}$ & $C$ & C & $C$ \\
\hline & 11 & $\mathrm{C}$ & $C$ & $C$ & $c$ & C & C & $\mathrm{U}$ \\
\hline & 12 & $\mathrm{U}$ & $\mathrm{R}$ & C & $\mathrm{R}$ & $\mathrm{R}$ & C & $\mathrm{R}$ \\
\hline \multirow[t]{5}{*}{ Oak plots } & 13 & $\mathrm{U}$ & $\mathrm{U}$ & $\mathrm{U}$ & C & C & U & $\mathrm{U}$ \\
\hline & 14 & $\mathrm{U}$ & $C$ & $C$ & c & C & C & U \\
\hline & 15 & C & C & $\mathrm{U}$ & C & C & C & U \\
\hline & 16 & $\mathrm{C}$ & $C$ & $C$ & $c$ & $C$ & U & $\mathrm{U}$ \\
\hline & 17 & C & C & $C$ & c & C & $\mathrm{U}$ & $\mathrm{U}$ \\
\hline
\end{tabular}

species (Hedenås et al. 2003; Snäll et al. 2003). This might be attributable to the fact that species distribution is highly influenced by characteristics of the landscape and habitat quality (Löbel et al. 2006; Wagner et al. 2006; Belinchón et al. 2009), and species specificity (Hanski 2005).

The low dispersal ability and establishment limitation of L. pulmonaria at the regional and local scales have been reported using a range of tools, including molecular data, dispersal data, and presence/absence data (Gu et al. 2001; Kalwij et al. 2005; Öckinger et al. 2005; Werth et al. 2006; Werth et al. 
2007). However, our results highlighted a random pattern of L. pulmonaria presence indicating that this lichen is probably more limited by its establishment ability than dispersal.

The studied plots contained a heterogeneously aged canopy, which resulted from the forest management history (Belinchón et al. 2009). The spatial pattern of tree diameters was randomly distributed in all plots examined. However, Mediterranean oak plots had a lower coefficient of variation for tree diameters and smaller mean diameters than beech plots, which was probably due to their historical use in firewood production. As a consequence, the ancient stumps maintain even-aged cohorts of trees (Table 1). The spatial pattern of lichen occurrence was independent of the distribution of suitable habitat. This was also shown for L. pulmonaria in boreal forests, suggesting that the microhabitat quality determines establishment (Gu et al. 2001; Öckinger et al. 2005; Werth et al. 2006). Dispersed propagules land on sites within a few metres of the dispersal source and this is independent of habitat quality (Edman et al. 2004; Werth et al. 2006; Jönsson et al. 2008). Instead, dispersal depends on local winds or animals (Werth et al. 2006; Heinken et al. 2007) and only those propagules that find adequate habitats will develop a new thallus (Scheidegger \& Werth 2009). This is independent of the long distance dispersal ability of this species (see dispersal kernels from Werth et al. (2006)). Therefore, short distance L. pulmonaria colonization could be linked to habitat quality, rather than tree location, which is not limited by dispersal. The colonization probability at this scale might not be simply correlated with tree diameter, because bark characteristics are an important factor linked to habitat quality during the successful lichen establishment. Tree size is a major determinant of lichen dynamics, which is mainly related to the availability of different microhabitats, including bark crevices, porosity, roughness, the time available for colonization, and the increased surface area made available with tree growth (Snäll et al. 2003; Ranius et al. 2008; Belinchón et al. 2009).

Scheidegger \& Werth (2009) summarized the most important factors affecting attachment, dispersal, and establishment of L. pulmonaria. They highlight the importance of substrate properties on the species distribution, rather than space-related factors, such as dispersal attributes. We found that, the smooth bark of young beech trees made propagule attachment very difficult, whereas large colonized trees were located close to a focal tree. Thus, beech tree diameter is a key parameter, because bark becomes coarser with age and larger trees have been available for colonization for a longer time period (Barkman 1958; Sillett et al. 2000; Gu et al. 2001; Belinchón et al. 2009; Fritz 2009). However, the characteristic rough bark of oak trees, even when young, seemed more suited to the establishment of L. pulmonaria. Previous studies assessed the importance of bark roughness on epiphytic colonization (Barkman 1958; Armstrong 1988) and found that young forests could be favourable to propagule establishment in some tree species (Hilmo \& Såstad 2001). According to our results, oak trees located close to larger trees were more commonly occupied by L. pulmonaria regardless of diameter. Overall, these results suggest that oak tree diameter is not important for the presence and cover by this lichen. Other studies focused on different epiphytic organisms, such as bryophytes or fungi, present very similar results that highlight the important effects of tree diameter and bark characteristics on the distribution of many species (i.e., Heegaard \& Hangelbroek 1999; Edman et al. 2004; Jönsson et al. 2008).

The spatial pattern of L. pulmonaria cover differed between beech and oak plots, independently of the tree structure in each plot. To some extent, lichen growth may also reflect the spatial pattern of past forest management activities. The cover of L. pulmonaria did not show a random pattern in the oak plots, which suggests that this species might not grow equally well on all oak trees. The rough bark of oak trees favours establishment, but propagules still need time and appropriate conditions to grow. The oak stands in our study were recently managed, resulting in a large number of trees with small diameters. Remnant trees colonized by L. pulmonaria may act as a source of propagules to inoculate the surrounding younger trees, but there had been little time for the lichen to establish and grow on these trees. This agreed with previous studies that assessed the ability of L. pulmonaria to persist on residual trees and to reestablish in areas disturbed by selective cutting (Kalwij et al. 2005; Wagner et al. 2006; Bolli et al. 2008). The lichen cover showed an aggregated pattern and the dispersal of the species was not limited at this local scale, so this might be an effective dispersal process in a young unsaturated system.

Lobaria pulmonaria cover in beech stands exhibited random, uniform, and clumped patterns. Most beech forests in the studied area were undisturbed for an extended time period, which made the forest structure more heterogeneous (variations in dbh classes; Table 1). Thus, the different spatial patterns found in each plot might reflect these variations in forest structure. In contrast to oak trees, the presence of a large beech tree might not ensure that nearby trees would bear L. pulmonaria thalli. Lichen establishment also depends on whether nearby beech trees possess suitable characteristics for L. pulmonaria propagule establishment (diameter, rough bark, etc).

In conclusion, our study suggests that the factors controlling the establishment likelihood and L. pulmonaria cover were complex at small spatial scales, and that these effects varied with changes in habitat quality, depending on the host tree considered. In other words, the relative importance of tree characteristics, such as bark and diameter, distance of host tree from a propagule source, and forest structure, was tree species-specific. L. pulmonaria presence/absence was highly influenced by tree characteristics, which further supports the hypothesis that this lichen species is mainly limited by habitat quality, rather than dispersal ability. Lichen growth is also highly dependent on forest management, which determines the time available for lichen colonization. L. pulmonaria colonization and growth are limited by different factors and bark roughness might be an important colonization determinant, but it may be less important during other parts of the life cycle. Thus, once the lichen is established, the growth of L. pulmonaria might depend on the forest microclimate. Microenvironmental conditions in oak and beech forests are different, so the growth of the lichen and its survival probability may also be different.

A variety of management strategies could be incorporated into landscape planning to facilitate conservation of this 
threatened lichen, especially in threatened forest ecosystems in the Mediterranean world where the habitat requirements of L. pulmonaria differ substantially between available host trees. The long-term persistence of small clusters of colonized oak trees might promote the future establishment and development of L. pulmonaria in remaining phorophytes in oak stands, because these will act as a propagule source. This may be a general rule for L. pulmonaria (Price \& Hochachka 2001; Edman et al. 2008; Fritz et al. 2008), but our results suggest that this approach may not work efficiently in beech stands. Thus, specific recommendations on the spatial pattern and density of remnant trees are urgently needed in order to take full advantage of their potential as a source of lichen propagules (Sillett et al. 2000; Hilmo \& Såstad 2001). The difficulty of $L$. pulmonaria beech tree colonization means that lichen dynamics largely depends on the availability of suitable bark microhabitats. Thus, lichen populations may need more time to recover in disturbed beech stands.

The random spatial distribution pattern of L. pulmonaria supports the conclusion that the small scale dispersal of this lichen is not spatially restricted, although it is dependent on habitat quality. This clearly shows that the existence of 'safe-sites' for bark establishment may affect the successful dispersal process in epiphytic species when patch-tracking metapopulations. Apparently, not all old trees offer a suitable substrate quality for these epiphytic lichen species. In fact, tree age is a complex factor to interpret, because it covaries with growth and the subsequent formation of different bark characteristics, such as bark crevices and roughness development (Johansson et al. 2009).

Unfortunately, the dispersal and germination processes of most lichens remain poorly understood (Gu et al. 2001) and we need further studies of dispersal capacity, germination conditions, photobiont availability, growth rates, and temporal studies to better understand the life cycle of lichens.

This study was focused on L. pulmonaria, but our approach shows how new spatial analysis tools can aid the analysis and interpretation of the spatial configuration of epiphyte populations of any species and their relationships with hosts. Partitioning out the spatial components of trees allowed us to identify some patterns in L. pulmonaria populations that might otherwise have been attributed to the pattern of the host trees, or obscured by the pattern. These results were particularly evident in the case of L. pulmonaria cover, which showed distinct patterns, although the spatial pattern of tree positions and sizes was completely random. Furthermore, testing the epiphyte spatial patterns against the fitted mixed models can provide insights on the adequacy of models for describing the incidence and dynamics of epiphyte populations. In our study, the results showed a close fit between the GLM models and the spatial pattern of L. pulmonaria presence/absence, and revealed divergences between the fitted models and the spatial pattern for cover in both beech and oak forests. This suggests that other factors absent from the fitted models may be affecting the spatial structure of the epiphyte populations. Nevertheless, applying our modelling approach opens up new possibilities of focussing on spatial patterns to improve knowledge of the potential role of dispersal on epiphytic organisms in general. This has important ecological applications for accurately understanding the underlying factors controlling epiphytic dynamics, which is needed to maintain viable population of these organisms.

\section{Acknowledgements}

We want to thank Mónica A.G. Otálora, Jesús Dimas, María Herrera, María Prieto and Rubén López for help with fieldwork. We also want to thank to Rebecca Mau for the English revision. This research was supported by the Dirección General del Medio Natural, Comunidad Autónoma de Castilla-La Mancha, Ministerio de Educación y Ciencia of Spain (projects CGL200766066-C04-04/BOS, CGL2009-13190-C03-01 and CGL200913190-C03-02), and Comunidad de Madrid (REMEDINAL 2 project S2009/AMB-1783-01/01/2010-31/12/2013).

\section{REFERENCES}

Armstrong RA, 1988. Substrate colonization, growth and competition. In: Galun M (ed.), Handbook of Lichenology, vol. II. CRC Press, Florida, pp. 3-16.

Baddeley A, Turner $R, 2005$. Spatstat: an $R$ packaged for analyzing spatial point patterns. Journal of Statistical Software 12: $1-42$.

Bailey RH, 1976. Ecological aspects of dispersal and establishment in lichens. In: Brown DH, Hawksworth DL, Bailey RH (eds), Lichenology: progress and problems. Academic Press, London, pp. 215-247.

Barkman JJ, 1958. Phytosociology and Ecology of Crytogamic Epiphytes. Koninklyke Van Gorcum and Comp, Assen.

Belinchón R, Martínez I, Otálora MAG, Aragón G, Dimas J, Escudero A, 2009. Fragment quality and matrix affect epiphytic performance in a Mediterranean forest landscape. American Journal of Botany 96: 1974-1982.

Bolli JC, Wagner HH, Kalwij JM, Werth S, Cherubini P, Scheidegger C, Rigling A, 2008. Growth dynamics after historic disturbance in a montane forest and its implications for an endangered epiphytic lichen. Botanica Helvetica 118: 111-127.

Costa Tenorio M, Morla C, Sainz H, 1998. Los bosques ibéricos: una interpretación geobotánica. Planeta, Barcelona.

Dale MRT, 1999. Spatial Pattern Analysis in Plant Ecology. Cambridge Univ. Press, Cambridge.

De la Cruz M, 2008. Métodos para analizar datos puntuales. In: Maestre FT, Escudero A, Bonet A (eds), Introducción al Análisis Espacial de datos en Ecología y Ciencias Ambientales: Métodos y Aplicaciones. Universidad Rey Juan Carlos, Madrid, pp. 76-127.

Denison WC, 2003. Apothecia and ascopsores of Lobaria oregana and Lobaria pulmonaria investigated. Mycologia 95: 513-518.

Dettki H, Klintberg P, Esseen PA, 2000. Are epiphytic lichens in young forests limited by local dispersal? Ecoscience 7: 317-325.

Diggle PJ, 1983. Statistical Analysis of Spatial Point Patterns. Academic Press, New York.

Dixon PM, 2002. Ripley's K function. In: El-Shaarawi AH, Piergorsh WW (eds), The Encyclopedia of Environmetrics. John Wiley and Sons Ltd, New York, pp. 1796-1803.

Edman M, Kruys N, Jonsson BG, 2004. Local dispersal sources strongly affect colonization patterns of wood-decaying fungi on spruce logs. Ecological Applications 14: 893-901.

Edman M, Eriksson AM, Villard MA, 2008. Effects of selection cutting on the abundance and fertility of indicator lichens Lobaria pulmonaria and Lobaria quercizans. Journal of Applied Ecology 45: 26-33.

Firbank LG, Watkinson AR, 1987. On the analysis of competition at the level of the individual plant. Oecologia 71: 308-317. 
Fritz O, 2009. Vertical distribution of epiphytic bryophytes and lichens emphasizes the importance of old beeches in conservation. Biodiversity and Conservation 18: 289-304.

Fritz O, Niklasson M, Churski M, 2008. Tree age is a key factor for the conservation of epiphytic lichens and bryophyts in beech forests. Applied Vegetation Science 12: 93-106.

Gauslaa Y, Solhaug K, 2001. Fungal melanins as a sun screen for symbiotic green algae in the lichen Lobaria pulmonaria. Oecologia 126: 462-471.

Gu WD, Kuusinen M, Konttinen T, Hanski I, 2001. Spatial pattern in the occurrence of the lichen Lobaria pulmonaria in managed and virgin boreal forests. Ecography 24: 139-150.

Hanski I, 2005. The Shrinking World: ecological consequences of habitat loss. . In: Excellence in Ecology 14. International Ecology Institute, Oldendorf/Luhe.

Hedenås H, Bolyukh VO, Jonsson BG, 2003. Spatial distribution of epiphytes on Populus tremula in relation to dispersal mode. Journal of Vegetation Science 14: 233-242.

Heegaard E, Hangelbroek HH, 1999. The distribution of Ulota crispa at a local scale in relation to both dispersal- and habitatrelated factors. Lindbergia 24: 65-74.

Heinken T, Rohner MS, Hoppert M, 2007. Red wood ants (Formica rufa group) disperse bryophyte and lichen fragments on a local scale. Nova Hedwigia 131: 147-163.

Hernández JE, Sainz H, 1978. Ecología de los hayedos meridionales ibéricos: el macizo de Ayllón. Ministerio de Agricultura, Ed. Servicio de publicaciones agrarias, Madrid.

Hilmo O, Såstad SM, 2001. Colonization of old-forest lichens in a young and an old boreal Picea abies forest: an experimental approach. Biological Conservation 102: 251-259.

Johansson P, 2008. Consequences of disturbance on epiphytic lichens in boreal and near boreal forests. Biological Conservation 141: 1933-1944.

Johansson P, Bergman K-O, Lättman H, Milberg P, 2009. Tree and site quality preferences of six epiphytic lichens growing on oaks in southeastern Sweden. Annals of Botany Fennici 46: 496-506.

Jönsson MT, Edman M, Jonsson BG, 2008. Colonization and extinction patterns of wood-decaying fungi in a boreal oldgrowth Picea abies forest. Journal of Ecology 96: 1065-1075.

Kalwij JM, Wagner HH, Scheidegger C, 2005. Effects of stand-level disturbances on the spatial distribution of a lichen indicator. Ecological Applications 15: 2015-2024.

Kuusinen M, 1996. Cyanobacterial macrolichens on Populus tremula as indicators of forest continuity in Finland. Biological Conservation 75: 43-49.

Lancaster J, Downes BJ, 2004. Spatial point pattern analysis of available and exploited resources. Ecography 27: 94-102.

Lättman H, Lindblom L, Mattsson JE, Milberg P, Skage M, Ekman S, 2009. Estimating the dispersal capacity of the rare lichen Cliostomum corrugatum. Biological Conservation 142: 1870-1878.

Levin SA, Muller-Landau HC, Nathan R, Chave J, 2003. The ecology and evolution of seed dispersal: a theoretical perspective. Annual Review of Ecology, Evolution and Systematics 34: 575-604.

Löbel S, Snäll T, Rydin H, 2006. Species richness pattern and metapopulation processes - evidence from epiphyte communities in boreo-nemoral forests. Ecography 29: 169-182.

Löbel S, Snäll T, Rydin H, 2009. Mating system, reproduction mode and diaspore size affect metacommunity diversity. Journal of Ecology 97: 176-185.

Martínez I, Aragón G, Sarrión FJ, Escudero A, Burgaz AR, Coppins B, 2003. Threatened lichens in central Spain. Cryptogamie Mycologie 24: 73-97.

Nathan R, Muller-Landau HC, 2000. Spatial patterns of seed dispersal, their determinants and consequences for recruitment. Trends in Ecology and Evolution 15: 278-285.

Öckinger E, Niklasson M, Nisson SG, 2005. Is local distribution of the epiphytic lichen Lobaria pulmonaria limited by dispersal capacity or habitat quality? Biodiversity and Conservation 14: 759-773.
Olano JM, Laskurain NA, Escudero A, De la Cruz M, 2009. Why and where do adult trees die in a young secondary temperate forest? The role of neighbourhood. Annals of Forest Science 66: 105.

Penttinen A, 2006. Statistics for marked point pattern. In: The Yearbook of the Finnish Statistical Society, pp. 70-91.

Pharo E, Zartman CE, 2007. Bryophytes in a changing landscape: the hierarchical effects of habitat fragmentation on ecological and evolutionary processes. Biological Conservation 135: 315-325.

Price K, Hochachka G, 2001. Epiphytic lichen abundance: effects of stand age and composition in coastal British Columbia. Ecological Applications 11: 904-913.

Purvis OW, Coppins BJ, Hawksworth DL, James PW, Moore DM, 1992. The Lichen Flora of Great Britain and Ireland. Natural History Museum Publications, London.

Ranius T, Johansson P, Niclas B, Niclasson M, 2008. The influence of tree age and microhabitat quality on the occurrence of crustose lichens associated with old oaks. Journal of Vegetation Science 19: 653-662.

Ripley BD, 1988. Statistical Inference for Spatial Processes. Cambridge Univ. Press, Cambridge.

Scheidegger C, 1995. Early development of transplanted isidioid soredia of Lobaria pulmonaria in an endangered population. Lichenologist 27: 361-374.

Scheidegger C, Werth S, 2009. Conservation strategies for lichens: insights from population biology. Fungal Biology Reviews 23: $55-66$.

Sillett SC, McCune B, Peck JE, Rambo TR, Ruchty A, 2000. Dispersal limitations of epiphytic lichens result in species dependent on old-growth forests. Ecological Applications 10: 789-799.

Snäll T, Ribeiro PJ, Rydin H, 2003. Spatial occurrence and colonisations in patch-tracking metapopulations: local conditions versus dispersal. Oikos 103: 566-578.

Snäll T, Hagström A, Rudolphi J, Rydin H, 2004. Distribution pattern of the epiphyte Neckera pennata on three spatial scales importance of past landscape structure, connectivity and local conditions. Ecography 27: 757-766

Snäll T, Ehrlén J, Rydin H, 2005. Colonization-extinction dynamics of and epiphyte metapopulation in a dynamic landscape. Ecology 86: 106-115.

Stewart AJA, John EA, Hutchings MJ, 2000. The world is heterogeneous: ecological consequences of living in a patchy environment. In: Hutchings MJ, John EA, Stewart AJA (eds), The Ecological Consequences of Environmental Heterogeneity. British Ecological Society, Oxford, pp. 1-8.

Tackenberg O, Poschlod P, Bonn S, 2003. Assessment of wind dispersal potential in plant species. Ecological Monographs 73: 191-205.

Tilman D, Kareiva PM, 1997. Spatial Ecology: the role of space in population dynamic and interspecific interactions. Princeton Univ Press, Princeton.

Upton G, Fingleton B, 1985. Spatial Data Analysis by Example: point pattern and quantitative data, vol. 1, John Wiley \& Sons, Chichester.

Walser JC, 2004. Molecular evidence for limited dispersal of vegetative propagules in the epiphytic lichen Lobaria pulmonaria. American Journal of Botany 9: 1273-1276.

Wagner HH, Werth S, Kalwij JM, Bolli JC, Scheidegger C, 2006. Modelling forest recolonization by an epiphytic lichen using a landscape genetic approach. Landscape Ecology 21: 849-865.

Werth S, Wagner HH, Gugerli F, Holderegger R, Csencsics D, Kalwij JM, Scheidegger C, 2006. Quantifying dispersal and establishment limitation in a population of an epiphytic lichen. Ecology 87: 2037-2046.

Werth S, Gugerli F, Holderegger R, Wagner HH, Csencsics D, Scheidegger C, 2007. Landscape-level gene flow in Lobaria pulmonaria, an epiphytic lichen. Molecular Ecology 16: 2807-2815.

Zoller S, Frey B, Scheidegger C, 2000. Juvenile development and diaspore survival in the threatened epiphytic lichen species Sticta fuliginosa, Leptogium saturninum and Menegazzia terebrata: conclusions for in situ conservation. Plant Biology 2: 496-503. 